\section{Mucocele of the appendix: a simple ultrasonographic diagnosis for a rare disease}

\author{
Bahjat Barakat, ${ }^{1}$ Raffaele Pezzilli \\ 'Department of Emergency, S. Orsola- \\ Malpighi University Hospital, Bologna; \\ ${ }^{2}$ Department of Digestive Diseases and \\ Internal Medicine, S. Orsola-Malpighi \\ University Hospital, Bologna, Italy
}

Appendiceal mucocele is a rare disease due to accumulation of mucus inside the appendix and it represents a heterogeneous group of histopathologic lesions including mucosal hyperplasia, cystadenoma and cystadenocarcinoma. Its prognosis depends on the pathological subtypes.

We report the case of a 54 year old man who visited the emergency room for a pain localized in the right side of the lower abdomen of $10 \mathrm{~h}$ duration; the pain worsened with cough and walk. He had fever of $37.7^{\circ} \mathrm{C}$. There was abdominal rigidity and guarding, and pain at digital rectal exam. Blood examination revealed only an increase in white blood cell count $(13.400 \mathrm{~mm} 3)$. The patient underwent transabdominal ultrasonography (US) and then contrast-enhanced computer tomography (CT) examination (Figures 1 and 2, respectively). The patient was subsequently operated on and the final diagnosis was that of appendiceal mucocele.

Usually, the most common symptom of appendiceal mucocele is the pain localized in the lower part of the abdomen; if there is no pain, the main finding is a palpable mass in the right lower quadrant and the preoperative diagnosis is given after abdominal US and confirmed with CT scan. ${ }^{1,2}$ In our case, the patient presented the typical US pattern characterized by a cystic lesion with the onion skin sign that is considered as a specific marker for appendiceal mucocele (Figure 1), ${ }^{1,2}$ while the CT imaging showed a capsulated cystic mass with or without calcification of the wall (Figure 2). ${ }^{3,4}$ In our case the imaging was pathological-

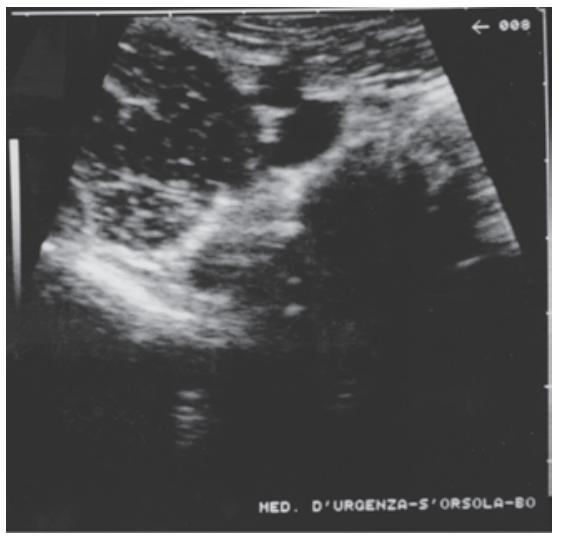

Figure 1. Ultrasonographic appearance of unilocular, ovoid, anechoic, numerous fine echo spots capsulated cystic mass with the onion skin sign in the appendiceal area.

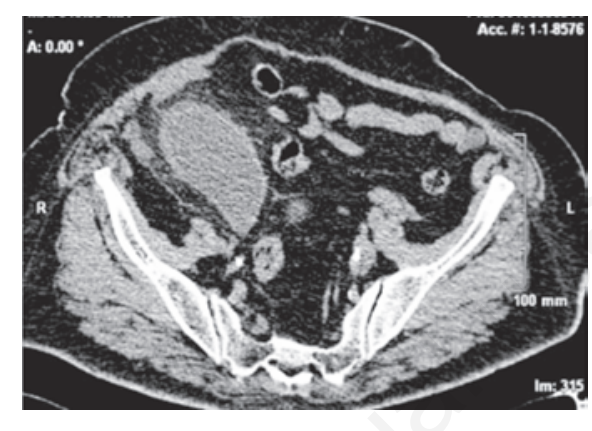

Figure 2. Contrast-enhanced computed tomography scan shows tubular dilatation of cystic mass of the appendix containing fluid.

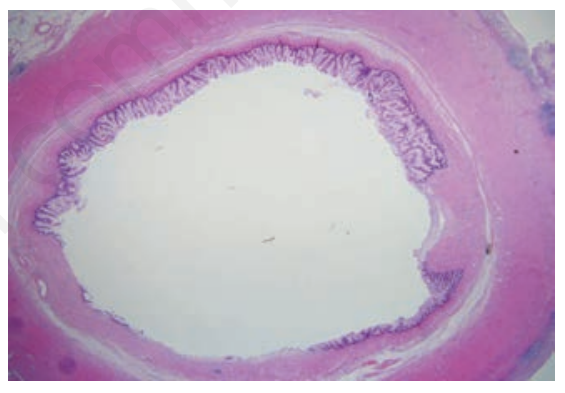

Figure 3. Pathological specimen demonstrates villiform mucin-secreting epithelium lining appendiceal lumen.
Correspondence: Raffaele Pezzilli, Department of Digestive Diseases and Internal Medicine, S. Orsola-Malpighi University Hospital, via Massarenti 9, 40138 Bologna, Italy. Tel. +39.051.6364148 - Fax: +39.051.6364148.

E-mail: raffaele.pezzilli@aosp.bo.it

Key words: mucocele, computed tomography, ultrasongraphy, clinical evaluation.

Conflict of interest: the authors declare no potential conflict of interests.

Received for publication: 4 June 2014.

Revision received: 4 September 2014.

Accepted for publication: 11 September 2014.

This work is licensed under a Creative Commons Attribution 3.0 License (by-nc 3.0).

(C) Copyright B. Barakat and R. Pezzili, 2014

Licensee PAGEPress, Italy

Emergency Care Journal 2014; 10:4406

doi:10.4081/ecj.2014.4406

ly confirmed (Figure 3). This case confirms that US is the best choice in emergency situation to diagnose the mucocele of the appendix. $^{5}$

\section{References}

1. Caspi B, Cassif E, Auslender R, et al. The onion skin sign: a specific sonographic marker of appendiceal mucocele. J Ultras Med 200;23:1117-21.

2. Sasaki K, Ishida H, Komatsusa T, et al. Appendiceal mucocele: sonographic findings. Abdom Imaging 2003;28:15-8.

3. Kunin N, Musolino A, Skufca J, Cisero N. Mucocele appendiculaire; images en chirurgie. J Chir-Paris 2003;140:47-70.

4. Zissin R, Gayer G, Kots E, et al. Imaging of mucocele of the appendix with emphasis on the CT findings; a report of 10 cases. Clin Radiol 1999;54:826-32.

5. Attarde V, Patil P, Apte A, et al. Sonographic appearance of a giant appendicular mucocele. J Clin Ultrasound 2011;39:290-2. 